\title{
Profit margins in Japanese retailing
}

\author{
Jeroen C.A. Potjes ${ }^{a}$ and A. Roy Thurik ${ }^{b}$ \\ ${ }^{a}$ Tinbergen Institute, Centre for Advanced Small Business Economics, ING Group, \\ Rotterdam, Netherlands \\ ${ }^{b}$ Research Institute for Small and Medium-Sized Business, Centre for Advanced Small Business \\ Economics, Rotterdam, Netherlands
}

Received December 1991; accepted May 1993

Abstract: Using a rich data source, we explain differences and developments in profit margins of medium-sized stores in Japan. We conclude that the protected environment enables the retailer to pass on all operating costs to the customers and to obtain a relatively high basic income. High service levels are positively related with high profit margins, illuminating the importance of service in Japan. Small store competition does not affect performance of medium-sized stores, because small stores operate under circumstances different from those of medium and large stores.

Keywords: Retailing; Japan; Profit margins; Medium-sized business; Panel data

JEL Classification: M31

\section{Introduction}

In recent years, Japanese retailing has become a topic of economic interest, because the retail system is supposed to be one of the sources of the trade imbalances of the US and the EC vis-à-vis Japan. In Batzer and Laumer (1989), Czinkota (1985), Dawson (1989), Kuribayashi (1991), Larke (1992), Maeda (1981), Tajima (1971), the US International Trade Commission (1990) and Yoshino (1971), the recent developments in the Japanese retail sector are described and the degree of changes is indicated. In Dodwell

Correspondence to: A.R. Thurik, Centre for Advanced Small Business Economics, Economic Faculty, Erasmus University Rotterdam, P.O. Box 1738, 3000 DR Rotterdam, Netherlands. Tel. (+31) 104081259 , fax $(+31) 104527746$.

Data have been obtained through financial support of Yoshida Nederland BV (YKK) and the Institute of Business Research at Aoyama Gakuin University. The authors are grateful to Prof. Dr. Yasuaki Suzuki for translating the data sources and his helpful comments. An early version of this paper was presented at the 2nd Annual Global Marketing Conference: The Japanese Distribution System of the American Marketing Association on 22-24 November 1991, in Honolulu, HI. The authors gratefully acknowledge useful comments of René A. Belderbos and an anonymous referee of this journal. 
Marketing Consultants (1988), a survey is given of the major retail and wholesale companies in Japan. In Potjes and Thurik (1991), a description of supermarkets in Japan is given. Business practices in the distributive sector are described in Czinkota and Woronoff (1986), Flath (1989), Flath and Nariu (1989) and Marvel (1993). Goldman (1991) describes the traditional internal political economy of Japanese retailing. In Flath (1990), Patrick and Rohlen (1987) and Potjes et al. (1992) explanations are given for the abundance of small stores in Japan. The bi-polar structure of small and large stores in Japanese retailing is discussed in Nishimura and Tachibana (1993). The development in small store presence is explained in Carree et al. (1993). Government regulations protecting small retail firms are described in Kirby (1984). The efficiency of the Japanese distribution sector is compared with the distribution sectors of Germany and the US in Ito and Maruyama (1992). Their analysis of profit margins showed that the Japanese distribution system is as efficient as the German and the American distribution systems. This is in contrast to assumptions in many other papers. The study by Nishimura (1993) using detailed data on Japanese and American retailing corroborates the findings of Ito and Maruyama (1992). However, his analysis also shows a rapid increase in the cost of distribution services in Japan for consumer goods.

On the whole, the retail sector in Japan is considered to have many features differing from retail systems in other developed countries. These features, to be discussed in Section 2, include the protection of small stores by government regulations; the inefficiency of the small retail stores; the typical Japanese strive for service, convenience and quality, leading to a wealth of small stores; and the tight relations between retailers and wholesalers. The purpose of our study is to determine the impact of these socio-economic and traditional features on the performance of the Japanese medium-sized retail entrepreneurs. We shall explain differences and developments of retail profit margins using a reduced form mark-up relationship that is based upon a relationship successfully applied in several studies on Dutch and German retailing ${ }^{1}$. Our relationship, presented in Section 3, allows to study the impact on retail profit margins of the protected environment the Japanese medium-sized retail entrepreneurs operate in; the service and convenience characteristics of the shop-type; the inefficiency of small stores and the competition between small, medium and large stores. Using a rich and extensive data set of 35 shop-types, covering almost the entire spectrum of shop-types and spanning 16 years, from 1973 until $1988^{2}$, we shall estimate our relationship. The estimation results will be discussed in Section 4. Section 5 will conclude the paper with some tentative remarks on the

${ }^{1}$ See Nooteboom (1985), Nooteboom et al. (1988) and Nooteboom and Thurik (1985).

2 See Table 3 for a list of shop-types and the appendix for data sources and variable definition. 
implications of close relations, high quality and high services for the Western exporter to Japan, and on the alleged inefficiency of Japanese retailing.

\section{Retailing in Japan}

The character of a country's retail system is determined not only by socio-economic aspects but by cultural and traditional features as well. As explained by Tajima (1971), the cultural and traditional background of Japan shaped a retail system quite different from that in other developed countries, e.g. the US, UK and Germany. The Japanese retail sector can be described as having a small but growing number of modern efficient superstores, supermarkets, specialty chain stores and convenience stores; a few large extravagant department stores, dealing in a wide range of products of the highest quality; and an abundance of small inefficient retail stores. In the current section, we shall describe the influence of four groups of economic agents on the Japanese retail system as it is now. These groups are government, retailers, customers, and suppliers of the retailer [viz wholesalers and manufacturers]. But first, we will position Japanese retailing in an international perspective.

\subsection{An international comparison}

In most studies on Japanese retailing [e.g. Batzer and Laumer (1989), Flath (1990), Goldman (1991) and the US International Trade Commission (1990)], the inefficient structure and the abundance of small stores is demonstrated by comparing the number of stores per 1000 inhabitants in Japan with those in the US, UK and Germany. Indeed, in such a comparison, Japanese retailing is a small-scale business as is shown in Table 1. However, we observe that the number of stores per 1000 inhabitants in France and the

Table 1

Japanese retailing in an international comparison: number of stores per 1000 inhabitants, average number of persons engaged, use of family labour and average sales value.

\begin{tabular}{lccc}
\hline Country & $\begin{array}{c}\text { Number of stores per } \\
\text { 1000 inhabitants }\end{array}$ & $\begin{array}{c}\text { Persons engaged } \\
\text { per establislunent }\end{array}$ & $\begin{array}{c}\text { Sales value } \\
\text { per establishment } \\
\text { (in 1985 ecu) }\end{array}$ \\
\hline Japan & 13.6 & 3.7 & 299 \\
USA & 3.5 & 12.9 & 1055 \\
United Kingdom & 6.0 & 6.8 & 422 \\
Germany & 6.2 & 6.0 & 552 \\
France & 10.2 & 2.8 & 344 \\
Netherlands & 10.6 & 2.9 & 291 \\
Italy & 16.7 & 2.3 & 219 \\
Spain & 19.1 & 3.1 & 105 \\
\hline
\end{tabular}

Sources: Census of Commerce (1985), Ravesloot and Vogelesang (1989). 
Table 2

The size distribution in Japanese retailing.

\begin{tabular}{lccccccc}
\hline $\begin{array}{l}\text { Distribution } \\
\text { by persons } \\
\text { engaged }\end{array}$ & \multicolumn{2}{c}{ Share in percentage (1972) } & & \multicolumn{3}{c}{ Share in percentage (1988) } \\
\cline { 2 - 3 } & $\begin{array}{c}\text { Number of } \\
\text { stores }\end{array}$ & $\begin{array}{c}\text { Persons } \\
\text { engaged }\end{array}$ & $\begin{array}{c}\text { Total } \\
\text { sales }\end{array}$ & $\begin{array}{c}\text { Number of } \\
\text { stores }\end{array}$ & $\begin{array}{c}\text { Persons } \\
\text { engaged }\end{array}$ & $\begin{array}{c}\text { Total } \\
\text { sales }\end{array}$ \\
\hline $1-2$ & 62.0 & 28.4 & 14.8 & & 54.0 & 21.0 & 11.2 \\
$3-4$ & 23.3 & 22.8 & 19.0 & & 26.1 & 20.8 & 16.8 \\
$5-9$ & 10.5 & 18.9 & 21.6 & & 13.2 & 19.5 & 21.0 \\
$10-19$ & 2.8 & 10.6 & 13.0 & & 4.3 & 13.5 & 14.8 \\
$20-49$ & 1.1 & 8.9 & 11.9 & & 1.9 & 13.3 & 14.8 \\
$50-99$ & 0.2 & 3.7 & 5.7 & & 0.3 & 5.1 & 6.5 \\
$>100$ & 0.1 & 6.7 & 13.9 & & 0.1 & 6.8 & 15.0 \\
\hline
\end{tabular}

Source: Census of Commerce 1972, 1988.

Netherlands is almost as high as in Japan and both Italy and Spain have considerably more stores per 1000 inhabitants than Japan. In sales value and number of persons engaged per establishment, the Japanese stores are considerably smaller than the American, German and British stores, about as large as the French and Dutch stores, and larger than the Italian and Spanish stores. These figures show that the Japanese retail sector is not as exceptional as it is often presented.

Nevertheless, the high number of small stores in Japan may contribute to the inefficiency of the entire Japanese distribution system. The importance of the small stores is summarised in Table 2 . We notice that in 54 percent of all stores only one or two persons were engaged in 1988. These small stores had a market share of not more than $\mathbf{1 1 . 2}$ percent. In Nishimura and Tachibana (1993) it is shown that the difference in labour productivity between large and small stores is relatively large in Japan, compared to France and the US. Table 2 also shows that the small store presence is in decline, because in 1972 , these small stores amounted to 62 percent of total store population having a retail market share of 14.8 percent. The labour productivity of these small stores is about 53 percent of the average labour productivity in retailing ${ }^{3}$. In the light of the low productivity it seems remarkable that a large number of small stores survives.

In comparison to many other countries, the variation in store size is large in Japan. There are many very small stores, but also a considerable number of very large stores. In Germany and the Netherlands, medium-sized stores are more prominent. However, the development in the Japanese store size distribution shows that the decrease in number of small stores resulted in an increase in number of medium-sized stores, indicating that small stores either grow in size or disappear and that the establishment of new small stores decreases, whereas the establishment of medium-sized stores increases.

\footnotetext{
${ }^{3}$ Labour productivity is measured as sales per person engaged.
} 
Therefore, medium-sized stores become more and more important in Japan [see also Carree et al. (1993)]. In this study we investigate profit margins of these medium-sized stores. In the Japanese case, we define medium-sized stores as stores having 3-19 persons engaged ${ }^{4}$. Their 1988 market share is 43.6 percent in number of stores, 53.8 percent in persons engaged and 52.6 percent in sales.

\subsection{The government}

Both after the 1968 Meiji revolution and the Second World War, the Japanese government dedicated its regulatory efforts towards international trade and industrialisation; internal trade was neglected [Hirschmeier and Yui (1975)]. Until now, government policies regulating internal trade are few. In European countries, potential retailers need a license for establishing a retail outlet and in many countries the owner has to have a kind of professional degree. Furthermore, in countries like Germany and the Netherlands, areas are designated as shopping districts and it is almost impossible to set up a store outside these areas. These types of regulations are, according to our knowledge, not existent in Japan for small stores.

As far as we know, there are only two regulations directly aimed at the retail industry in Japan. These are the license system to sell rice, alcoholic liquors and tobacco products and the much disputed Large-Scale Retail Store Law (Dai ten hō). The license system results in a protection of the licensed stores from competitors in the neighbourhood, because licenses are only supplied to a restricted number of establishments per neighbourhood.

The Large-Scale Retail Store Law and its implications have been thoroughly discussed in several papers [e.g. Ito and Maruyama (1992), Kirby (1984), Kuribayashi (1991), Larke (1992) and the US International Trade Commission (1990)]. The law puts operations of large retail stores [e.g. department stores and superstores] under strict regulations [e.g. limited opening hours]. In a so-called participation procedure, the neighbouring small retailers and the large retailer have to find a compromise about the size of the store, the opening times and other conditions under which the large retail store is going to operate. This lengthens the establishment process of a large scale store. In some cases it took more than 10 years to obtain permission to establish the store. This law has been under heavy attack by US trade negotiators in particular and is revised in 1991.

Japanese government policies are directed to stimulate and protect small and medium-sized business. This is not unrelated to the fact that the leading Liberal Democratic Party (LDP) depends on the votes of the small and

${ }^{4}$ Our definition of medium-sized stores is motivated by the substantial difference in labour productivity of stores with 1 or 2 persons engaged compared with stores with more than 3 persons engaged and by the fact that more than half of the number of stores has 1-2 persons engaged and only 2.3 percent of the stores has 20 or more persons engaged. 
medium-sized entrepreneurs to keep its majority in parliament [Kosai (1987), Patrick and Rohlen (1987)]. The Large Scale Retail Store Law exemplifies the political power of the retailers' lobby on the LDP. Furthermore, small enterprises do not have to keep accounts of their transactions. Tax regulations favour small enterprises. Also, government facilitates the continuation of family stores, because residential taxes are lower if one operates a business at home. The government also encourages small enterprises to continue business: legacy duties are considerably lower when the continuation of a small enterprise is at stake [see Nishimura and Tachibana (1993)].

Renting practices favour the continuation of small-sized stores in Japan. Starting to rent a site in Japan involves the payment of large sums of key-money. This key-money can be seen as an assurance for a long lasting and close relation between landlord and tenant. Rents are rising rapidly with sky-rocketing land-prices, not only in Tokyo but also elsewhere in Japan. However, rents increase by only a small amount, as long as the same tenant is renting the place. This is favourable for already established retailers, but it obstructs the intentions of retailers to enlarge their store. Growth implies the requirement of more selling area, meaning that one has to move to a different site. This implies much higher rents and again the payment of key-money, which frustrates the growth of the small and medium-sized retail stores in particular.

Furthermore, government subsidises and facilitates the modernisation of stores of small and medium-sized retailers, in particular when it is carried out concordant with the shopping-street associations, the so-called Shötengai kai.

Many of the regulations aiming at the stimulation of small business also have a positive effect on medium-sized stores. Medium-sized stores are not hampered in their operations by the LSRS Law and they benefit from modernisation subsidies.

\subsection{The Japanese retailer}

Several Japanese researchers distinguish between a retail enterprise, a family store and a side-job store ${ }^{5}$. The family store and side-job store are operated by a family and are aimed to provide their main source of income or an additional income, respectively. The basic motivation of the retail entrepreneur is to make profits. The operation of the family and side-job stores is fundamentally different from that of the retail enterprise, and the difference affects productivity, costs, profits and the competitive environment. Our data reflect the smaller stores managed by retail entrepreneurs and the larger family stores.

Labour and floorspace productivity are much lower for the family and side-job stores than for the retail enterprises. The sales per person engaged

\footnotetext{
${ }^{5}$ We would like to thank Professor Dr. Yasuaki Suzuki of Aoyama Gakuin University for pointing this out.
} 
in family and side-job stores is about half the sales per person engaged of the retail enterprises and the sales per square meter selling area of family and side-job stores are about 60 percent of the sales per square meter in stores of retail entrepreneurs ${ }^{6}$. There are two reasons for this large difference in labour and floorspace productivity between the family and side-job stores and the retail enterprises ${ }^{7}$ : First, family stores and side-job stores use mainly family labour whereas retail enterprises have to hire regular employees. Second, the unprofitable family and side-job retailers are generally reluctant to leave business [Carree et al. (1993), Nishimura and Tachibana (1993)], although an increasing number of small store retailers retire without a successor [Suzuki (1991)].

The labour costs of the retail enterprises are based upon regular wages per working hour. This is not the case for the family and side-job stores. Their labour force consists for more than sixty percent of shopkeepers and their families. For the small family and side-job stores, with only 1 or 2 persons engaged, this is more than ninety percent. The shopkeepers and family members make long hours to meet a yearly turnover that secures a satisfactory family income. Many stores, however, are not profitable enough to generate a satisfactory income level. Shopkeepers of these stores often have a position elsewhere in addition to their shopkeeping activities. In some instances, the income of the additional jobs exceeds the income generated by the store. These stores can be called side-job stores. Therefore, the sales per person engaged can be lower for the family and side-job stores than for the retail enterprises, whose employees have to be paid per hour of work.

Many of the small-scale family and side-job retailers invested all their savings in the store. They operate the store from their own house and family life is intertwined with the operation of the store. As explained earlier, the legal conditions to operate a small store encourage the continuation of the store even if it is not profitable. This implies that the medium-sized retailer has to compete for market share not only with a growing number of efficient large scale retail stores, but also with a large number of inefficient and probably unprofitable small stores.

\subsection{The Japanese customer}

In Flath (1990), it is explained that Japanese stores not only serve as the last chain in the distribution channel, but have a local warehouse function as wcll. The Japanesc live in small houses because of the scarcity of land. There is little room to stock large quantities of food. Therefore, most Japanese housewives do their shopping daily and buy the necessary products in

6 Data are from Census of Commerce (1988).

7 Our discussion of the small scale family enterprises in retailing is based upon the discussion in Patrick and Rohlen (1987). 
quantities just sufficient for the needs of that particular day. In this way, stores serve as local warehouses for the neighbourhood. Furthermore, the Japanese diet contains a relatively large share of fish and other perishable products. The Japanese are very keen on freshness, and the daily shopping habit enables them to consume these fresh products every day. To visit stores frequently, the accessibility of the stores has to be very good. Driving and especially parking in Japan is troublesome, because of the narrow winding streets and the lack of parking lots. The number of Japanese that shop by car is relatively small, although younger generations and people in rural areas use cars more often. Therefore, the neighbourhoods are penetrated with small stores ${ }^{8}$, so that the customers can do their shopping on foot. This feature of Japanese shopping is not only common in small villages, but in large cilies as Tokyo as well, because all Japanese cities can be subdivided into small areas that have a persisting neighbourhood structure [Bestor (1989) and Dore (1958)].

The small stores in the neighbourhoods depend for the major share of turnover on the patronage of local clients. Therefore, Japanese retailers dedicate most of their time to fostering the relations with them. The side lines of business can be very well adapted to the needs of the regular clients, thus strengthening their relation. Many Japanese retailers sell a large range of products next to their main line of business. Many rice stores for example also deal in beverages, candy, tobacco products or groceries. Also, the side lines of business are often not connected with the main line of business (i.e. the dry cleaner selling beverages and tobacco products).

The Japanese customer values service and quality highly. Batzer and Laumer (1989), Douglas and Craig (1990), Kuribayashi (1991), Montgomery (1991) and the US International Irade Commission (1990) all stress the importance of quality and service. In Simon (1986), eleven marketing instruments are evaluated for the Japanese market; quality and service rank highly, whereas price is assumed to be the least important marketing instrument. This relates very well to the Japanese saying 'okyaku-sama wa kamisama desu (the customer is god)'.

The service package of most Japanese stores is large ${ }^{9}$. Next to home

8 The overwhelming success in Japan of the convenience chain store corporations (e.g. Seven Eleven, Family Mart and Lawson) can be attributed to these shopping habits of the Japanese and in particular to the local warehouse function of Japanese stores.

9 The about two hundred prestigious department stores are a fine example of the extent and quality of retail services in Japan. The department store is a huge shopping palace and every customer is extremely well treated. Personnel has been trained in wrapping, in using the correct honorific when addressing the customers and in making bows at the appropriate angle when customers enter, buy something, and leave. The department store does not compete in price nor in the assortment composition. Kather, the department store competes in the extent and quality of the services it offers. For example, every department store advertises its special wrappings for the gift-giving seasons, thus differentiating itself from the other department stores.) 
deliveries and special orders, retailers often arrange parcel services and the development of photographs. On the financial side, most stores, even the small ones, accept credit cards. Other stores give personal credit to their clients. Furthermore, the services of the small stores include long opening hours. Whereas the opening hours of large-scale stores are restricted to about 9 hours a day, 77 percent of the small stores is opened 10 hours a day and even 42 percent of the small stores is opened at least 12 hours a day, six days a week ${ }^{10}$. Of course, most of these retailers are prepared to serve their regular customers even after closing time.

\subsection{The wholesaler and the manufacturer}

The enormous number of small stores and the general smallness of the stores also asks for a widespread wholesale network. In Japan, most products pass three or more wholesalers on their way from manufacturer to retailer. The relations between retailers and wholesalers are tight. The importance of the relations in the Japanese distribution sector demonstrates the traditional character of its internal political economy [Goldman (1991)]. Wholesalers and manufacturers often take over the risk from the retailer by giving credit on stocks. Distribution practices like the return of unsold goods and resale price maintenance are common in Japan [Flath (1989), Flath and Nariu (1989), Kuribayashi (1991), Larke (1992) and Marvel (1993)]. Both retailer and customer have little space for keeping stocks. The wholesalers are accommodated to this, because they deliver their products to the retailers fast, frequently and in small proportions ${ }^{11}$. These distribution practices of the wholesalers give the retailers a wide and reliable assortment composition at low costs and low risk of having to disappoint a customer. In return, the retailer provides valuable information on the sales of his products to his wholesaler and the manufacturer. Important information about the products, such as defects and tastes, reaches the Japanese manufacturer quickly through the close relations of the retailer with his clients and the close relations in the distribution channel. This is one of the reasons why Japanese manufacturers can rapidly detect changes in fashion and adapt their products accordingly.

To summarise, the Japanese retailer has little to fear from direct compctitors. His yearly sales volume is secured by the close relations the retailer has with his clients and a general governmental protection from large-scale retailers. Service, quality and convenience are key aspects in the Japanese distribution system. Furthermore, there is a large difference in productivity

10 Data are from the 1988 Census of Commerce.

$11 \mathrm{Kao}$, the largest detergent manufacturer in Japan, for instance, delivers the day after the order is placed to about two hundred thousand retailers all over Japan, even if the order only consists of four or five items. 
percentage of sales

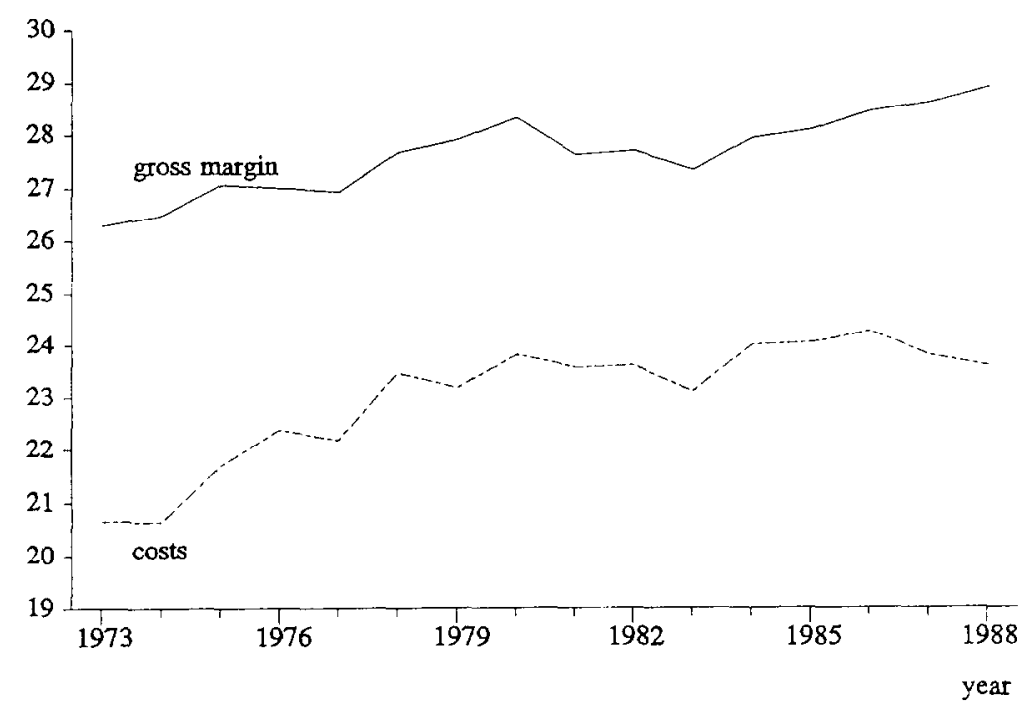

Fig. 1. The development of average percentage gross margins and average percentage costs of the average medium-sized enterprise in Japanese retailing (1973-1988). Source: Own computations based on Small and Medium-Sized Enterprise Agency (1975 through 1990).

between small- and large-scale retailers: the small-scale retailers are less efficient.

\section{A relationship to explain retail profit margins in Japan}

In Figure 1, the development of weighted average percentage operating costs ${ }^{12}$ and weighted ${ }^{13}$ average percentage gross margins ${ }^{14}$ of medium-sized stores in 35 shop-types over the years is given. We see that average percentage gross margins were rising gradually from 26.3 percent in 1973 to 28.9 percent in 1988. The average operating costs rose from 20.7 percent in 1973 to 24.3 percent in 1986 and then dropped to 23.6 percent in 1988 . Interestingly, net margins, defined as percentage gross margin minus operating costs, were 5.6 and 5.8 percent in 1973 and 1974, respectively, then declined gradually to 3.9 percent in 1984 and from 1986 onwards net margins recovered rapidly to 5.3 percent in 1988 .

12 For means of convenience we use the simple term operating costs to indicate operating costs minus the reward for shopkeepers and family labour as a percentage of sales.

13 To obtain an average that is comparable with total medium-sized retailing, we weighed the data with the respective market shares in medium-sized retailing.

14 Percentage gross margin is defined as the difference between sales value and purchase costs as a percentage of sales. 
Table 3

Percentage gross margins, percentage operating costs, percentage net margins and market share in sales value of medium-sized stores for 35 shop-types in 1988.

\begin{tabular}{|c|c|c|c|c|}
\hline Shop type & $\begin{array}{l}\text { Percentage } \\
\text { ross margin }\end{array}$ & $\begin{array}{c}\text { Percentage } \\
\text { operating } \\
\text { costs }\end{array}$ & $\begin{array}{l}\text { Percentage } \\
\text { net margin }\end{array}$ & $\begin{array}{l}\text { Market share } \\
\text { of medium- } \\
\text { sized stores }\end{array}$ \\
\hline Rice and barley stores & 15.0 & 13.1 & 1.9 & 70.5 \\
\hline Alcoholic liquors stores & 19.0 & 15.5 & 3.5 & 71.6 \\
\hline Grocery stores & 21.0 & 17.3 & 3.7 & 23.5 \\
\hline Vegetable and fruit stores & 21.3 & 16.6 & 4.7 & 71.2 \\
\hline Convenience stores & 21.6 & 17.9 & 3.7 & 71.7 \\
\hline Supermarkets & 22.9 & 20.5 & 2.4 & 33.9 \\
\hline Fresh fish stores & 25.4 & 18.2 & 7.2 & 70.1 \\
\hline Meat stores & 28.0 & 23.7 & 4.3 & 71.3 \\
\hline Tea stores & 32.9 & 23.5 & 9.4 & 58.5 \\
\hline Poultry stores & 45.6 & 38.7 & 6.9 & 62.5 \\
\hline Confectionery and bakery stores & 48.6 & 35.9 & 12.7 & 61.2 \\
\hline Haberdashery and accessory stores & 25.7 & 21.8 & 3.9 & 47.5 \\
\hline Clothing stores & 29.5 & 25.0 & 4.5 & 61.4 \\
\hline Haberdashery stores & 29.7 & 24.7 & 5.0 & 47.5 \\
\hline Japanese style footwear stores & 33.6 & 28.0 & 5.6 & 44.8 \\
\hline Shoe stores & 34.1 & 28.2 & 5.9 & 78.2 \\
\hline Bedding stores & 34.6 & 29.8 & 4.8 & 61.9 \\
\hline Female and child's clothing stores & 35.0 & 29.2 & 5.8 & 59.0 \\
\hline Bags and small cases stores & 36.9 & 30.9 & 6.0 & 74.6 \\
\hline Dry goods stores & 39.7 & 31.7 & 8.0 & 69.8 \\
\hline Mens clothing stores & 41.9 & 32.8 & 9.1 & 68.7 \\
\hline Book stores & 21.9 & 19.4 & 2.5 & 65.7 \\
\hline Paper and stationary stores & 22.6 & 17.9 & 4.7 & 66.3 \\
\hline Camera and photographic supply stores & 23.8 & 19.6 & 4.2 & 59.1 \\
\hline Electrical household appliances stores & 24.1 & 21.6 & 2.5 & 62.8 \\
\hline Sporting goods stores & 24.7 & 22.0 & 2.7 & 66.4 \\
\hline Drug stores & 25.6 & 19.4 & 6.2 & 67.1 \\
\hline Hardware and kitchenware stores & 26.0 & 19.1 & 6.9 & 55.3 \\
\hline Furniture stores & 30.2 & 24.7 & 5.5 & 59.8 \\
\hline Musical instrument stores & 30.8 & 27.9 & 2.9 & 64.8 \\
\hline Bicycle stores & 31.0 & 21.1 & 9.9 & 62.5 \\
\hline Toiletry stores & 31.5 & 25.3 & 6.2 & 60.9 \\
\hline Chinaware and glassware stores & 32.9 & 27.3 & 5.6 & 70.9 \\
\hline Toys and amusement goods stores & 34.6 & 30.9 & 3.7 & 71.5 \\
\hline Watch, eyeglass and optical goods stores & res 46.0 & 37.6 & 8.4 & 69.7 \\
\hline
\end{tabular}

Source: Small and Medium Sized Enterprise Agency (1990) and Census of Commerce (1988). Percentage gross margins, percentage operating costs and percentage net margins are gross margins, operating costs and net margins respectively as a percentage of sales value.

1 The percentage net margin is defined as percentage gross margin minus percentage operating costs.

${ }_{2}^{2}$ Medium-sized stores are defined as stores with 3-19 persons engaged.

Percentage gross margins in Japanese retailing vary widely among the different shop-types. In Table 3, percentage gross margins and percentage operating costs in 1988 are given for the 35 shop-types of our data set. Percentage gross margins vary from 14.4 percent for rice and barley stores to 
47.5 for confectionary and bakery stores. These two shop-types also have the lowest and highest average operating costs per sales volume of 10.9 and 39.4 percent, respectively. However, net margins differ from 0.9 percent for musical instrument stores to $\mathbf{1 2 . 7}$ percent for confectionary and bakery stores.

In this section, we shall describe a mark-up relationship used to explain the variation in gross margins over time and across shop-types. Our relationship is based upon a mark-up relationship given by Nooteboom (1985). The retail market is assumed to be composed of numerous local oligopolies. The specification of aggregated demand and supply functions for these types of markets is complex, and therefore the mark-up relationship is in the reduced form including both demand and supply effects. Our relationship differs from that of Nooteboom (1985) because it incorporates specific Japanese characteristics.

The mark-up relationship first presented in Nooteboom (1985) can be used for the explanation of percentage gross margin per type of shop, in both cross-section and time series studies. The mark-up relationship has been tested and confirmed using Dutch and German retail data ${ }^{15}$. It explains the average percentage gross margin per type of shop as a profit mark-up on average operating costs, which excludes a reward for shopkeepers' labour, as a percentage of sales. The profit mark-up consists of four elements, i.e., a basic reward, a shop-type effect, a life cycle effect and a business cycle effect:

the basic reward relates to the opportunity costs of the retailer's and his family's labour;

the shop-type effect originates from the fact that a more varied range of products, a higher service level and a better positioning on the market are positively valued by the customer and require a higher percentage profit mark-up to achieve a given return on investment for the retailer;

the life cycle effect is related to the presence of a bonus on novelty during the penetration phase, the disappearance of this bonus during the phase of saturation and the shrinkage of profit mark-up during the phase of decline;

the business cycle effect relates to the idea that the size of the profit mark-up depends on the economic situation. Price competition will be more intense in a contracting market, because retailers attempt to sustain sales volume.

We adapted the mark-up model to make it suitable for our study of profit margins of Japanese medium-sized retail stores. We added variables that enable to discuss to what extent retail profit margins are affected by the close relations between the retailer and his clients, the alleged inefficiency of the small-scale retailers, the competition between size classes and the specific demand factors of the Japanese customers. The mark-up relationship to be

15 See also Den Hertog and Thurik (1992), Nooteboom et al. (1988) and Nooteboom and Thurik (1985). 
estimated and tested for medium-sized stores in Japan has the following form:

$$
\begin{aligned}
\mu_{i t}= & \alpha_{0}+\alpha_{1} \kappa_{i t}+\alpha_{2} \frac{\omega_{t}}{q_{i t}}+\alpha_{3} S T_{i t}+\alpha_{4} S L_{i t}+\alpha_{5} C L_{i t}+\alpha_{6} D_{i t} \\
& +\alpha_{7} A_{i t}+\alpha_{8} L_{i t}+\alpha_{9} E C S_{i t}+\alpha_{10} F_{i t}+\alpha_{11} \stackrel{\circ}{M}_{i t}+\alpha_{12} \Delta M S_{i t} \\
& +\alpha_{13} \Delta M L_{i t}+\alpha_{14} \stackrel{\circ}{C}_{t}+\alpha_{15} d_{t}^{1974}+\epsilon_{i t}
\end{aligned}
$$

where $i$ indicates shop-type (there are 35 shop-types) and $t$ indicates year (1974, 1976, 1979, 1982, 1985 and 1988). The variables are given below ${ }^{16}$ :

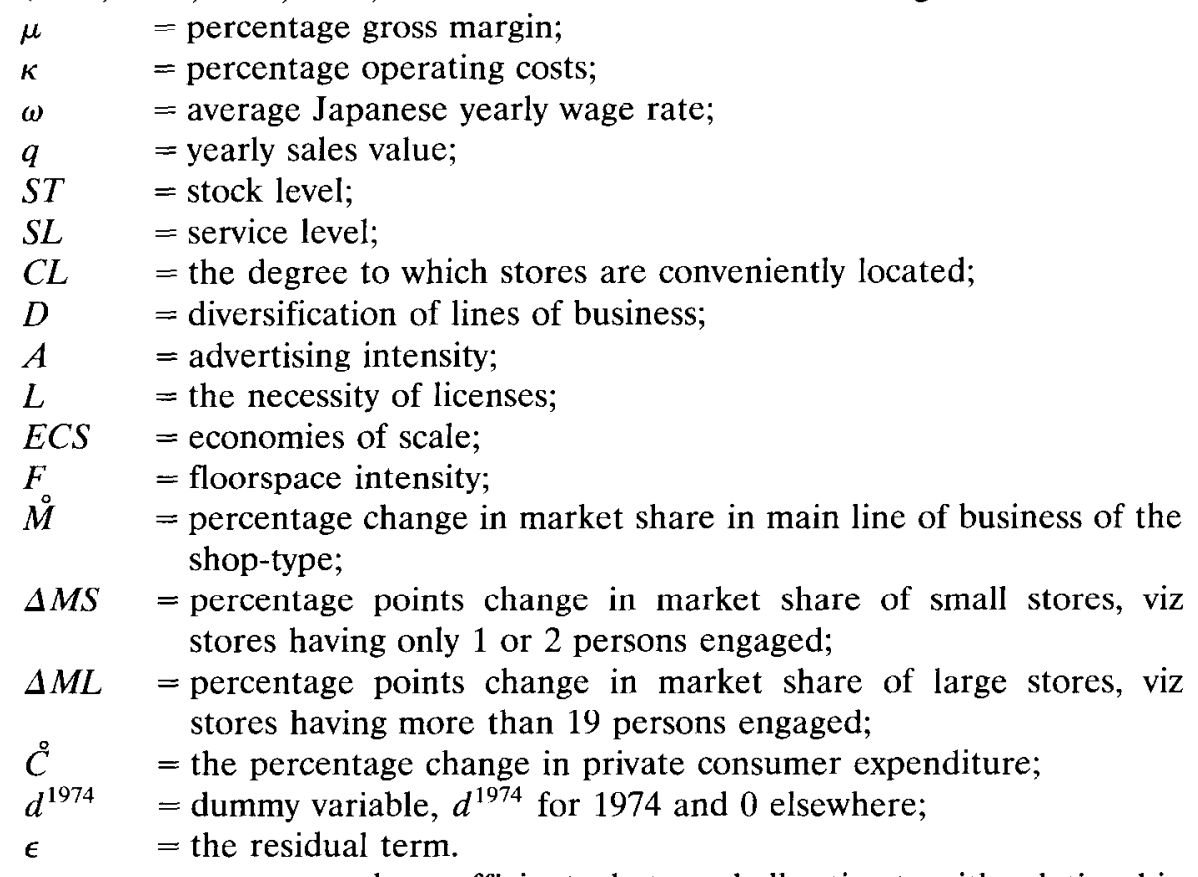
$\alpha_{0}, \alpha_{1}, \ldots, \alpha_{15}$ are the coefficients that we shall estimate with relationship (1). In the remainder of this section we shall discuss the variables and formulate hypotheses concerning the coefficients to be estimated.

$\alpha_{1}$, Operating costs, $\kappa$ : In this full costs mark-up relationship we assume that operating costs, excluding a reward for retailcr's and family's labour, arc fully compensated in the gross margin. This implies that the coefficient $\alpha_{1}$ equals unity.

16 In the remainder of this paper we shall not use subscripts in the formulas, unless they are needed for clarification. All variables are averages over the stores in the respective shop-types, unless indicated otherwise. 
$\alpha_{2}$, Basic reward: The operating costs, $\kappa$, do not include a remuneration for the labour of the shopkeeper and his family. Therefore, we shall use our model to estimate a reward for shopkeeper's and his family's labour by decomposing the profit margin into a part depending only on average wage rate in Japan, and a part depending on shop-type characteristics. The opportunity costs for retailer's and his family's labour are reflected by $\omega$, the average wage rate in Japan. The basic reward for retailer's and his family's income, independent of shop-type characteristics, has to relate to his opportunity costs. We assume that there is a basic reward, $\alpha_{2} \omega$, that is equal for all shop-types. Therefore, the coefficient $\alpha_{2}$ is assumed to be the basic reward for shopkeeper's and family's income as a percentage of the average yearly wage rate, $\omega$, in Japan. We hypothesise the coefficient $\alpha_{2}$ to be in excess of zero. Probably, it will be up to 100 percent implying the basic reward being about equal to the average wage rate. The second part of the retailer's income depends on the characteristics of his shop-type and on the stage in life and business cycle.

$\alpha_{3}$, Stock level, ST: In earlier studies ${ }^{17}$, stock level $S T$, defined as the stock-sales ratio, is used as the indicator of shop-type effect. The underlying reason for this is that when the level of inventory relative to sales is high, and hence inventory turnover is low, one needs a higher net profit over sales to achieve a given target return on capital (supply side). Also a high stock level accompanies a deeper and wider range of the assortment composition at a higher service level (demand side). The customer is assumed to show his apprcciation through a declining sensitivity for price levels. Therefore, the coefficient $\alpha_{3}$ is assumed to be higher than zero.

$\alpha_{4}$, Service level, SL: In Section 2, we described that Japanese consumers value service and quality highly and that service is considered to be a more important marketing instrument than price in Japan. We shall test whether shop-types with a high service level, $S L$, have higher percentage gross margins than shop-types with a low service level. We measure service level, $S L$, as number of persons engaged per square meter selling area. This ratio is influenced by several service enhancing aspects. First, if stores in a shop-type have long opening hours, more people are needed per square meter selling area. The second aspect concerns the amount of extra services supplied to the customer, like home deliveries, information about the products sold, wrapping services, etc. Both factors give the shop-type a positive image to the customer and strengthen the relation between customer and retailer. Therefore, we assume that this will lift the pressure to keep margins low and the coefficient $\alpha_{4}$ is assumed to be higher than zero.

17 See Carree and Thurik (1990), Den Hertog and Thurik (1990), Nooteboom et al. (1988) and Nooteboom and Thurik (1985). 
$\alpha_{5}$, Convenience of store location, $C L$ : In Section 2, we explained that the Japanese appreciate the convenience of having stores nearby. We assume that shop-types with stores located evenly all over Japan are a kind of convenience stores. They often have a monopoly position in their immediate neighbourhood and experience a limited downward pressure on profit margins. Shopkeepers of these conveniently located stores live near their customers, and the customers are able to frequent these stores daily. Both features strengthen the relation between customer and retailer.

Other types of store will be found in concentrated area's ${ }^{18}$; we call them shopping stores. Shopping stores have to be highly price competitive, because customers can search for the best store at low costs. There is no strong relation between retailer and customer. The area where most shopping stores can be found, is the ward area ( $k u$-area) of Tokyo. As an indicator of convenient location, we shall use the relative shop-type market share of stores located outside the Tokyo ward area, $C L$. We assume the coefficient $\alpha_{5}$ to be higher than zero, which means that conveniently located stores, that are represented in all areas of Japan, have a higher profit mark-up than shopping stores concentrated in shopping districts.

$\alpha_{6}$, Diversification, $D$ : Several shop-types offer a range of products wider than their main line of business. Stores are able to differentiate from their immediate competitors by choosing their supplementary product lines, because the supplementary assortment can differ among the stores within one shop-type. A higher degree of diversification of the assortment composition, $D$, allows the retailer to strengthen his ties with his circle of clients, because the side-lines of business can be tailored to his clients' needs. Diversification is considered to be an entry barrier. Hence, we assume that the coefficient $\alpha_{6}$ will be higher than zero.

$\alpha_{7}$, Advertising intensity, $A$ : Advertising is used to give information about the products sold, which enhances services to the customers and strengthens the relation between the retailer and his clients. Furthermore, advertising is used to position the store on its market and to distinguish the store from other stores, which is seen as a barrier to entry in many studies on manufacturing industries ${ }^{19}$. The entry barrier and service effect of advertising intensity are assumed to stimulate profits. We assume that the coefficient $\alpha_{7}$ will be higher than zero.

Advertising costs are also included in total operating costs. This enables to study the compensation of advertising expenditures in the gross margin. We assume that the risk averse retailers will overcompensate their advertising

18 A fine example of a concentration of shopping stores is the Akihabara electrical goods centre in Tokyo, a two block area with about 200 stores, all selling audio and video products. This is the area to go in Japan to buy the newest consumer electronics at the lowest prices.

19 In Comanor and Wilson (1967), theoretical as well as empirical evidence is given that the advertising intensity has a positive effect on profitability in the manufacturing industries. 
expenditures in the gross margin and the proportion of overcompensation is represented by the coefficient $\alpha_{7}$.

$\alpha_{8}$, Licenses, $L$ : Licenses are needed for selling tobacco products, alcoholic liquors and rice as is explained in Section 2. We shall estimate the effect of licenses by using the dummy variable $L$, which has the value 1 for the shop-types of rice stores and alcoholic liquor stores and 0 for the other shop-types. We hypothesise that margins are higher in the shop-types that need a licence, because the license system protects them from potential entrants and therefore the coefficient $\alpha_{8}$ is supposed to be higher than zero ${ }^{20}$.

The variables $S L, C L, D, A$ and $L$ reflect the product differentiation advantages of established sellers and as such they can be characterised as barriers to entry. In the industrial economics literature ${ }^{21}$, two other important sources of entry barriers have been discussed for the manufacturing industries: scale economies and capital requirements. In this paper we shall test if these two sources of barriers to entry are also positively correlated with gross margins in Japanese retailing.

$\alpha_{9}$, Economies of scale, ECS: We use a the ratio between large and small store labour productivity per shop-type as proxy variable for economies of scale. This variable amounts to 2 for many shop-types, illustrating the inefficiency of small stores. We assume the coefficient $\alpha_{9}$ to be higher than zero, because high economies of scale indicate high barriers to entry.

$\alpha_{10}$, Floorspace intensity, $F$ : Most of the capital requirements of a store are connected with the size of the selling area ${ }^{22}$. We assume that floorspace intensity, measured by the ratio floorspace in square meters per million yen sales value in prices of 1985, reflects the store's capital requirements. This is a barrier to entry and will have a positive effect on the level of profit margins.

In examining the data, we found a time-serial pattern in our shop-type variables. We therefore corrected $S T_{i t}, S L_{i r}, C L_{i t}, D_{i t}, E C S_{i 1}$, and $F_{i t}$ by subtracting the yearly averages: $\overline{S T}_{t}, \overline{S L}_{t}, \overline{C L}_{t}, \bar{D}_{t}, \overline{E C S}_{t}$, and $\bar{F}_{t}$ because we are interested in the differences of the variables between shop-types and not in their time-serial pattern ${ }^{23}$.

${ }^{20}$ In Potjes et al. (1990), a positive effect of licenses on floorspace productivity of Japanese convenience stores is found. It is even shown that licenses for selling tobacco and alcoholic liquors have a positive effect on the floorspace productivity of the other products of the convenience store.

21 See Schmalensee (1989) for an extensive survey.

2) Other capital requirements in the retail setting are the inventories of the store. The variable stock level, $S T$, in our relationship is related to the inventories of the store, and can be associated with an entry barrier too.

23 We also should have corrected advertising intensity, $A$, in this way. However, the typical interpretation of the coefficient $\alpha_{7}$ in our analysis, being the degree of overcompensation of advertising expenditures in the gross margin, is not possible if the variable is corrected. We examined the time-serial pattern of the advertising intensity and found no major fluctuation over time. Therefore, we did not make the correction for advertising intensity. 
$\alpha_{11}$, Life cycle effect of shop-type, $M$ : In previous retail studies ${ }^{24}$, it has not been possible to find data reflecting the growth in market share of all shop-types. Our data contain the market share of the shop-type, $M_{i t}$, defined as the share of the shop-type in the total sales of the main line of business of the shop-type. For example, $M_{i t}$ for fish stores is the market share of fish stores in the total fish sales in the whole retail sector. We assume that if the percentage growth in market share, $\dot{M}_{i t}$, is positive, the shop-type is in its penetration phase and there is a bonus on novelty, During the phase of saturation this bonus fades away. During the phase of decline the profit mark-up shrinks duc to the compctition of novel types of tradc. We assumc the parameter $\alpha_{11}$ to be in excess of zero.

$\alpha_{12}, \alpha_{13}$, Competition between size classes, $\triangle M S, \Delta M L$ : Our data reflect the gross margins of the medium-sized retail enterprises. This enables to study the effect of competition between small-, medium-, and large-sized stores. Small stores are defined as stores with 1 or 2 persons engaged, medium-sized stores are stores with 3 to 19 persons engaged and large stores as stores with 20 or more persons engaged. The effect of competition on profit margins of the medium-sized retail enterprises is studied using the expression $\alpha_{12} \Delta M S$ $+\alpha_{13} \Delta M L$. We assume that the coefficients $\alpha_{12}$ and $\alpha_{13}$ are both negative because, if market shares of either small or large stores grow, the position of medium-sized stores is relatively weakened, which results in a downward pressure on the level of profit margins.

In Section 2, we discussed that the small store retailers operate their stores in a way fundamentally different from that of the medium- and large-sized retail stores. Although the large store labour and floorspace productivity are much higher, the small retailers survive because of flexible use of family labour, cheap selling area and favourable taxation policies. Distinguishing the competition effect in two parts, we are able to establish whether competition from either small or large stores has the largest impact on the profit level of medium-sized stores.

$\alpha_{14}$, Business cycle effect, $\stackrel{\circ}{\mathrm{C}}$ : In a growing market, stores can expand more easily without competing for market share with other stores. With growing demand it is more easy to set higher prices. Therefore, we include the growth rate of real private consumption, $\stackrel{\mathscr{C}}{\mathrm{C}}$, to investigate this effect and we assume that $\alpha_{14}$ is higher than zero.

$\alpha_{15}$, Year dummy for 1974, $d^{1974}$ : in 1973, the Japanese economy was hit by the first oil crises. This led to a negative growth and a high level of price inflation. In 1974, this price inflation was 24 percent. Examination of the data showed significantly higher profit margins for this year, which led to the introduction of a dummy to control for the effect of this economic shock.

24 See for instance Nooteboom et al. (1988) and Nooteboom and Thurik (1985). 
In regional studies for one shop-type [Lamm (1981), Marion (1989) and Marvel (1989)], a positive correlation is found between prices and concentration in retailing. In Newmark (1990), however, no significant effect of concentration on prices was found. As mentioned in Ferguson (1988), it is difficult to define market concentration. This is especially so for retailing because markets are geographically segmented. We do not have the geographical characteristics because we are studying average profit margins over Japan. Furthermore, the size of the geographical markets differs per shoptype. The geographical market of a department store covers a whole region whereas the geographical market of a convenience store covers only a few blocks of a typical ward. We are not able to study the effect of concentration on profit margins in more detail.

\section{Estimation results}

We estimated the coefficients $\alpha_{0}, \alpha_{1}, \ldots, \alpha_{15}$ of relationship (1) with a large panel data set of 35 shop-types and six years, viz 1974, 1976, 1979, 1982, 1985 and 1988. Part of the data is taken from the Small and Medium Entreprise Agency (1975 through 1990) and part is taken from the Census of Commerce $(1972,1974,1976,1979,1982,1985$ and 1988). The 35 shop types covered 79.8 percent of the 1988 total sales value in retailing ${ }^{25}$. The medium-sized stores had an average market share 57.6 percent of the total sales in these shop-types. The individual market shares varied from 23.5 percent for the grocery stores to 78.2 percent of shoe stores, as is shown in Table 3. To estimate relationship (1), we weighted the data with the market share of the respective shop-type's medium-sized stores in total retailing. In this way, the estimated coefficients provide a fair representation of the effects in an average Japanese medium-sized store. Furthermore, we corrected for autocorrelation ${ }^{26}$. The results are summarised in Table 4.

$\alpha_{1}$, Operating costs: The coefficient $\alpha_{1}$ does not differ significantly from one. This means that the medium-sized Japancse retailer not only aims at compensating his cost completely in his gross margin, but also that he is able to do so because government protection and a monopoly position in his circle of clients do not give a strong downward pressure on profit margins.

25 For the total sales value in retailing we excluded the sales of department stores, petrol stations and molor vehicle stores.

26 Several techniques for panel data analysis [Judge et al. (1985), Chapter 13], have been used to estimate the coefficients. These include the error components model and the within-and-between method. Clearly, coefficient estimates differ across these methods, but they do not affect our major conclusions. In addition, using a slightly different model, we estimated the effects on a larger data set by including the intermediary years and interpolating the data of the Census of Commerce. These results are similar to the results in this paper and are presented in Potjes and Thurik (1992). 
Table 4

Hypotheses and estimation results of relationship (1).

\begin{tabular}{|c|c|c|c|c|}
\hline Variable & Influence & Hypothesis & Coefficient ${ }^{1}$ & $\begin{array}{l}\text { Standard } \\
\text { deviation }\end{array}$ \\
\hline & Intercept & & 0.626 & 0.631 \\
\hline$\kappa$ & Operating costs & $\alpha_{1}=1$ & $1.020 * *$ & 0.025 \\
\hline$\omega / q$ & Basic reward & $\alpha_{2}>0$ & $91.0 * *$ & 9.9 \\
\hline$S T$ & Stock level & $\alpha_{3}>0$ & 0.016 & 0.019 \\
\hline$S L$ & Service level & $\alpha_{4}>0$ & $0.185^{*}$ & 0.073 \\
\hline$C L$ & Convenient location & $\alpha_{5}>0$ & $0.095 * *$ & 0.032 \\
\hline$D$ & Diversification & $\alpha_{6}>0$ & $0.044 * *$ & 0.010 \\
\hline$A$ & Advertising intensity & $\alpha_{7}>0$ & $0.731 * *$ & 0.171 \\
\hline$L$ & License & $\alpha_{8}>0$ & -0.197 & 0.327 \\
\hline$E C S$ & Economies of scale & $\alpha_{9}>0$ & $0.657 *$ & 0.344 \\
\hline$F$ & Floorspace intensity & $\alpha_{10}>0$ & $-0.447 *$ & 0.209 \\
\hline$\stackrel{\circ}{M}$ & Life cycle of shop-type & $\alpha_{11}>0$ & -0.018 & 0.052 \\
\hline$\Delta M S$ & Change share small stores & $\alpha_{12}<0$ & -0.112 & 0.148 \\
\hline$\Delta M L$ & Change share large stores & $\alpha_{13}<0$ & $-0.196 *$ & 0.082 \\
\hline$\stackrel{\stackrel{\circ}{C}}{ }$ & Growth of consumption & $\alpha_{14}>0$ & $0.220 * *$ & 0.055 \\
\hline$d^{1974}$ & Dummy for 1974 & $\alpha_{15}>0$ & $2.584 * *$ & 0.361 \\
\hline$n$ & Number of observations & & 210 & \\
\hline$R^{2}$ & Goodness of fit & & 0.97 & \\
\hline
\end{tabular}

${ }^{1}$ For coefficients that differ from zero on the 1 percent significance level $* *$ is printed next to the estimation result and $*$ is printed when the coefficient differs from zero at the 5 percent significance level.

$\alpha_{2}$, Basic reward: The coefficient $\alpha_{2}$ is significantly higher than zero, which indicates that there is a basic reward for entrepreneurial labour and income out of family labour in retailing. This reward is 91 percent of the average wage rate, $\omega_{t}$ but not significantly lower than this average wage rate.

In Nooteboom, Kleijweg and Thurik (1988), a basic reward of about 37 percent of the average income has been found for the Dutch retail practice. If we compare this with results found in the present study, we see that the Japanese basic reward is considerably higher than that in the Netherlands. This confirms our hypothesis that the Japanese retailers will primarily focus on obtaining a long term basic income that is close to the average income in Japan. It also indicates that the Japanese retailer works in a more protected environment in which he is able to pass on all his costs and to obtain an ample basic remuncration for his efforts.

$\alpha_{3}$, Stock level: Stock level, $S T$, does not have an effect on gross margins.

$\alpha_{4}$, Service level: The coefficient $\alpha_{4}$ is significantly higher than zero, which supports the hypothesis that service level, $S L$, has a positive effect on the level of gross margins in Japan. This also means that service level is a relevant shop-type characteristic when explaining profit margins and that the Japanese consumers are prepared to pay higher prices for extra services.

$\alpha_{5}$, Convenience of store location: The coefficient $\alpha_{5}$ is significantly higher than zero. This means that shop-types on convenient locations, $C L$, gain 
higher gross margins, which is a confirmation of the local warehouse theory of Flath (1990) and the price competition effect of shopping stores.

$\alpha_{6}$, Diversification: The effect of side-lines of business next to the main line of business on gross margin is positive $\left[\alpha_{6}\right.$ is significantly higher than zero]. This is very well understandable from the point of view of the Japanese customers. Customers are not obliged to frequent other stores if their regular stores provide additional products that are tailored to their needs. Therefore, retailers will use their side line products to foster their relations with their regular customers.

$\alpha_{\gamma}$, Advertising intensity: The coefficient $\alpha_{7}$ is significantly higher than zero, which confirms the hypothesis that advertising intensity, $A$, has a positive effect on gross margins. We see that advertising costs are more than fully compensated in the gross margin. Through the operating costs advertising costs are already compensated 1.02 times and through the advertising coefficient $\alpha_{7}$ by a factor 0.73 . This implies that advertising costs are overcompensated in the gross margin by a factor of 0.75 . Not all effects of his advertising efforts will be directly traceable for the retailer. In view of the risky nature of advertising the Japanese retailers will ask an extra premium for advertising efforts. The reason for the Japanese retailer to advertise is probably not to enlarge market share but to strengthen the relations with his regular customers.

$\alpha_{8}$, Licenses: By estimating the coefficient $\alpha_{8}$, we tested whether the rice stores and alcoholic liquors stores have a higher gross margin, than other shop-types. The coefficient $\alpha_{8}$ does not differ significantly from zero, so the hypothesis that licenses create an entry barrier and thus higher profits can be gained is not supported.

In protected industries, costs tend to rise, because the lack of competition does not stimulate the entrepreneur to keep costs low. This might explain why we do not find the expected positive sign for the coefficient $\alpha_{8}$ but a negative sign. Furthermore, many rice and alcoholic liquor stores turned into a convenience store while keeping their licence. These convenience stores are severe competitors for the remaining regular rice and alcoholic liquor stores, because most people will visit the convenience stores daily and buy also their rice and alcoholic liquors.

$\alpha_{9}$, Economies of scale: Economies of scale, ECS, have a positive effect on gross margins [ $\alpha_{9}$ is significantly higher than zero]. This means that economies of scale are not only a barrier to entry that influences profit margins in the manufacturing industries [as is often documented], but also in retailing ${ }^{27}$.

27 Interestingly, the level of economies of scale in a shop-type does not have a direct impact on the developments in market share between the size classes as is found in Carree et al. (1993). This probably has to do with the reluctance of small Japanese retailers to exit the market. 
$\alpha_{10}$, Floorspace intensity: In the preceding section we have provided arguments for a positive effect of floorspace intensity on profit margins, which was based upon the fact that floorspace intensity is a barrier to entry. However, the coefficient $\alpha_{10}$ is significantly below zero, rejecting our hypothesis.

In our analysis we measure floorspace intensity, $F$, as the selling area sales ratio, which is the inverse of floorspace productivity. Investigation of the data showed that $F$ indicates the shop-types with low productivity rather than shop-types with high demand for capital. In shop-types with low productivity price competition will be more severe to regain sales volume, which puts a downward pressure on the profit margins. Many family and side-job retailers are reluctant to leave the market even when their capital utilisation is seemingly too low to be profitable. The current tax system however makes it worthwhile to them to stay in business [Nishimura and Tachibana (1993)]. This reluctance to exit lowers the overall floorspace productivity in the sector. This explanation of the negative sign, combined with the significant effect found in the empirical analysis stresses the importance of recognising the inefficiency of parts of the Japanese retail sector.

$\alpha_{11}$, Life cycle effect of shop-type: The coefficient $\alpha_{11}$ does not differ significantly from zero, and therefore we do not find support for a life cycle effect of shop-type in our analysis.

$\alpha_{12}, \alpha_{13}$, Competition between size classes: We see that changes in market share of large scale retailers affect the profit margins of medium-sized retailers, whereas competition of small retailers seem to have no effect on profitability of medium-sized stores [the coefficient $\alpha_{13}$ for the change in market share of large retailers, $\Delta M L$, is significantly lower than zero and the coefficient $\alpha_{12}$ for change in market share of small retailers, $\Delta M S$, does not differ significantly from zero]. This indicates that medium-sized stores and large scale stores operate on the same markets whereas small stores do not. A similar empirical finding can be found in Nishimura and Tachibana (1993). They conclude that labour productivity of small stores is not affected by wage level and rents of large stores and vice versa.

$\alpha_{14}$, Business cycle effect: The coefficient $\alpha_{14}$ of percentage growth in private consumption, $\dot{C}_{t}$, is significantly higher than zero. This confirms the busincss cycle effects in the gross margin. A percentage growth of private consumption of one percent results in a gross margin growth of 0.22 percent of sales.

$\alpha_{15}$, Year dummy for 1974: We find the coefficient $\alpha_{15}$ to be significantly higher than zero. Japanese consumption was tempered, during the oil crisis in 1973-1974,. The percentage growth in private consumption was even negative, which gave a downward pressure on profit margins. However, retailers were able to obtain high net profit margins as pointed out in Figure 1. A reason for this phenomenon might be the sales of stocks at current 
inflated prices. These stocks had been bought at considerably lower prices before the rise in inflation.

In sum, the mark-up relationship (1) is very suitable to explain profit margins in Japanese retailing. The goodness of fit, $R^{2}$, equals 0.97 . Of the signs of the fifteen coefficients estimated twelve are in accordance with the hypotheses discussed in Section 3 and ten significantly at the 5 percent level. Three coefficients show values not in accordance with our hypotheses but two of those are not significantly different from zero. Only once this value is significantly different from zero. This discrepancy on the effect of floorspace intensity on profit margins has been commented upon in the present Section.

We conclude that the protected environment enables the retailer to pass on all operating costs to the customers and to obtain a relatively high basic income. High service levels are positively related with high profit margins, illuminating the importance of service in Japan. Small store competition does not affect performance of medium-sized stores, because small stores operate under circumstances different from those of medium and large stores.

\section{Concluding remarks}

The Japanese retailer operates in an environment of low competition. This low competitive environment is created by government protection of small and medium-sized retailers, the close relations between the retailer and his clients in the neighbourhood, and the close relations between the retailer and his suppliers in the region. Therefore, the medium-sized Japanese retailer is relatively flexible in his price setting behaviour. He is able to fully compensate his operating costs in his profit margin, to obtain an relatively high basic income, independent of scale and use of market opportunities.

The level of service, the degree of advertising intensity, the convenience of store location and the range of the assortment composition strengthen the relation between customer and retailer and weaken the downward pressure on retail profit margins. They all have a decisive contribution to the explanation of Japanese profit margins. This has some implications for companies willing to export to Japan because traders and manufacturers have to have close relations with their retailers. Furthermore, the retailer deals with a Japanesc company with a reputation well-known to him rather than with the unknown Western company. Western companies exporting to Japan do have to invest in the distribution system, to build strong relations not only with retailers but also with their wholesalers. The costs of such a distribution network will be high in Japan because it has to consist of a large number of stores to reach the customers and to provide them with all services needed.

Finally, we showed that competition of small stores, as opposed to that of large stores, does not affect the profit level of medium-sized stores. This supports the idea that small stores operate in a different market segment 


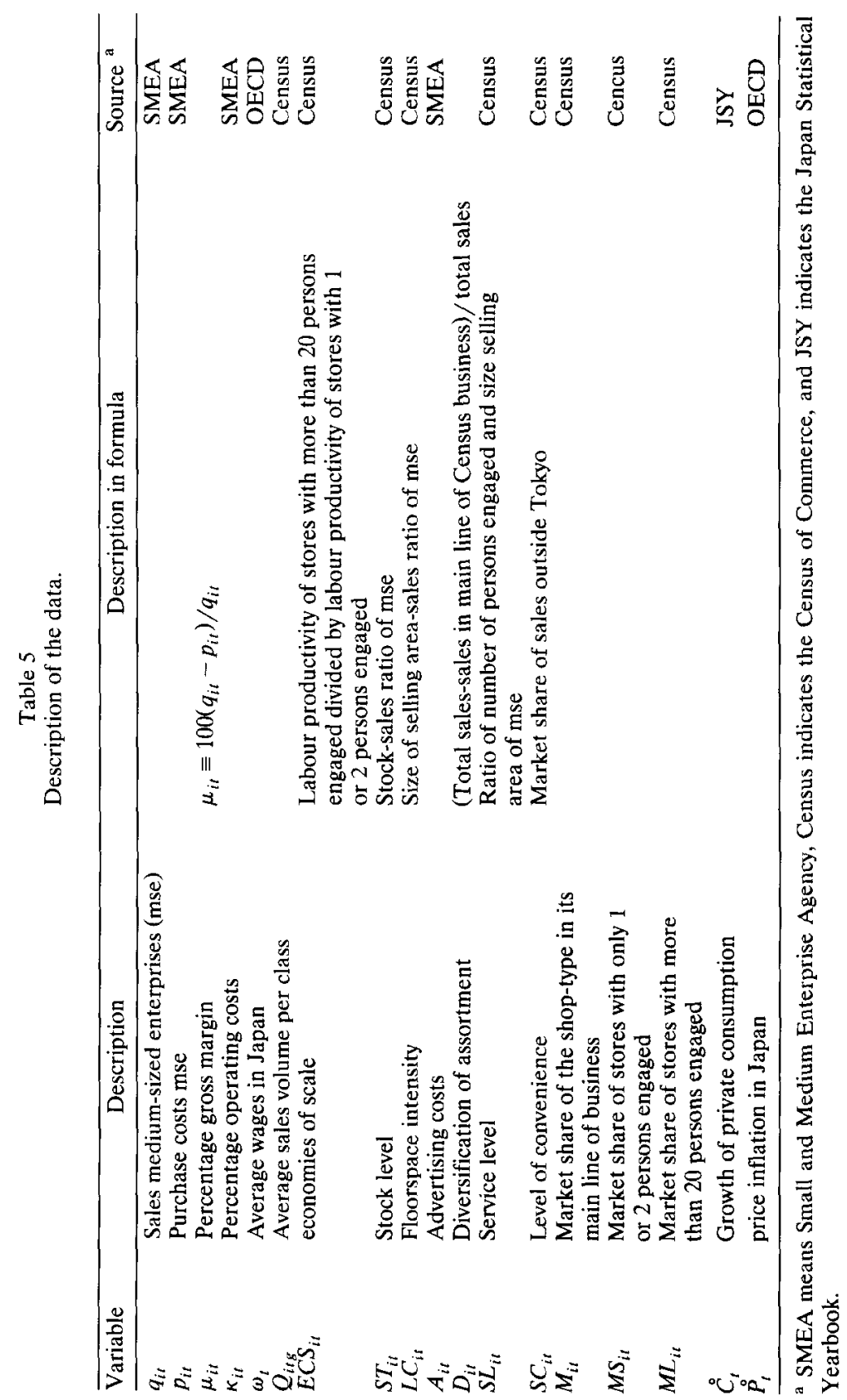


than medium and large-scale stores. The small stores serve the traditional retail market segments considered to be in decline. Medium and large stores however compete for new customers and apply modern retail techniques. They appear not to be involved in direct competition with small retailers.

\section{Appendix - Data}

The data are taken from four different sources: the Small and Medium Enterprise Agency (SMEA), the Census of Commerce (Census), the Japan Statistical Yearbook (JSY) and the OECD.

The Small and Medium-Sized Enterprise Agency samples data from small and medium-sized enterprises. Annually, it publishes average cost accounts of small and medium-sized enterprises for about 200 industries. These data tend to reflect the larger medium-sized enterprises better than the small enterprises. For smaller businesses data are not very reliable, because for small businesses bookkeeping is not obligatory and therefore bookkeeping practices of the small firms are not very well developed. The Research and Statistics Department of MITI gathers data for the Census of Commerce once every two and since 1976 once every three years.

In Table 5 all variables used in the regression analysis are defined and the sources are given.

\section{References}

Batzer, E. and H. Laumer, 1989, Marketing strategies and distribution channels of foreign companies in Japan (Westview Press, Boulder, CO).

Bestor, T.C., 1989, Neighborhood Tokyo (Stanford University Press, Stanford, CA).

Carree, M.A. and A.R. Thurik, 1990, Market volatility, entry barriers and retail profit margins, Report 9061/A (Econometric Institute, Erasmus University Rotterdam, Rotterdam, Netherlands).

Carree, M.A., J.C.A. Potjes and A.R. Thurik, 1993, Small store presence in Japan, Economic Letters 41, 329-334

Census of Commerce, 1972, 1974, 1976, 1979, 1985 and 1988, Compiled by the Research and Statistics Department (Minister's Secretariat, Ministry of International Trade and Industry, Tokyo).

Comanor, W.S. and T.A. Wilson, 1967, Advertising, market structure and performance, Review of Economics and Statistics 49, 423-440.

Czinkota, M.R., 1985, Distribution in Japan: Problems and changes, Columbia Journal of World Business 20(3), 65-71.

Czinkota, M.R. and J. Woronoff, 1986, Japan's market: the distribution system (Praeger, New York).

Dawson, J.A., 1989, Japanese distribution; effectual yes, but is it efficient? in: The Japanese market: a guide to distribution (London) 10-25.

Den Hertog, R.G.J. and A.R. Thurik, 1990, A comparison between Dutch and West German retail price setting, in: N.E. Synodinos, C.F. Keown, T.H. Becker, K.G. Grunert, T.E. Muller, J.H. Yu, eds, Proceedings of the Third Symposium on Cross-Cultural Consumer and Business Studies (Honolulu, HI) 185-196.

Den Hertog, R.G.J. and A.R. Thurik, 1992, Expectations and retail profit margins, International Review of Retail, Distribution and Consumer Research 2(3), 265-282. 
Dodwell Marketing Consultants, 1988, Retail distribution in Japan (Dodwell Marketing Consultants, Tokyo).

Dore, R.P., 1958, City life in Japan: a study of a Tokyo ward (University of California Press, Berkeley, CA).

Douglas, S.P. and C.S. Craig, 1990, Achieving success in Japanese consumer markets, Japan and the World Economy 2, 1-21.

Ferguson, P.R., 1988, Industrial economics: issues and perspectives (MacMillan Education Ltd., London).

Flath, D., 1989, Vertical restraints in Japan, Japan and the World Economy 1, 187-203.

Flath, D., 1990, Why are there so many retail stores in Japan? Japan and the World Economy 2 , 365-386.

Flath, D. and T. Nariu, 1989, Returns policy in the Japanese marketing system, Journal of the Japanese and International Economies 3, 49-63.

Goldman, A., 1991, Japan's distribution system: Institutional structure, internal political economy and modernization, Journal of Retailing 67(2), 154-183.

Hirschmeier, J. and T. Yui, 1975, The development of Japanese business, 1600-1973 (Harvard University Press, Cambridge, MA).

Ito, T. and M. Maruyama, 1992, Is the Japanese distribution system really inefficient? in: P. Krugman, ed., The United States and Japan: trade and investment in the 1990s (University of Chicago Press, Chicago, IL).

Japan Statistical Yearbook, 1990, Management Statistics Bureau and Coordination Agency (ees.) (Japan Statistical Association, Tokyo).

Judge G.G., R.C. Hill, W.E. Griffiths, H. Lütkepohl and T.C. Lee, 1985, The theory and practice of econometrics, 2nd ed. (John Wiley and Sons, Inc., New York).

Kirby, D.A., 1984, Government policies towards the small retail business in Japan, International Small Business Journal 2, 44-58.

Kosai, Y., 1987, The politics of economic management, in: K. Yamamura and Y. Yasuba, eds., The political economy of Japan; Vol. 1: The domestic transformation (Stanford University Press, Stanford, CA) 555-592.

Kuribayashi, S., 1991, Present situation and future prospect of Japan's distribution system, Japan and the World Economy 3, 39-60.

Lamm, R.M., 1981, Prices and concentration in the food retailing industry, Journal of Industrial Economics 29, 67-78.

Larke, R., 1992, Japanese distribution: an appraisal with view to the future, Working Paper 9202 (Institute for Retail Studies, University of Stirling, UK).

Maeda, K., 1981, The evolution of retailing industries in Japan, in: A. Okochi and K. Shimokawa eds., Development of mass marketing: the automobile and retailing industries, Proceedings of the Fuji Conference (University of Tokyo Press, Tokyo) 265-289.

Marion, B.W., 1989, The concentration-price relationship in food retailing, in: L.W. Weiss ed., Concentration and price (MIT Press, Cambridge, MA) 185-193.

Marvel, H.P., 1989, Concentration and price in gasoline retailing, in: L.W. Weiss ed., Concentration and price (MIT Press, Cambridge, MA) 179-185.

Marvel, H.P., 1993, Contracts and control in Japanese distribution, Managerial and Decision Economics 14, 151-162.

Montgomery, D.B., 1991, Understanding the Japanese as customers, competitors and collaborators, Japan and the World Economy 3, 61-91.

Newmark, C.M., 1990, A new test of the price-concentration relationship in grocery retailing, Economic Letters 33, 369-373.

Nishimura, K.G., 1993, The distribution system of Japan and the United States: A comparative study from the viewpoint of huyers, Japan and the World Economy 5, 265-288.

Nishimura, K.G. and T. Tachibana, 1993, Entry Regulations, Tax Distortion, and the Bipolarized Market: The Case of Japanese Retail Sector, New York, The Center for Japan-U.S. Business and Economic Studies (forthcoming).

Nootcboom, B., 1985, A mark-up model of retail margins, Applied Economics 17, 647-667.

Nooteboom, B., A. Kleijweg and A.R. Thurik, 1988, Normal costs and demand effects in price setting, European Economic Review 32, 999-1011. 
Nooteboom, B. and A.R. Thurik, 1985, Retail margins during recession and growth, Economic Letters 17, 281-284.

OECD, 1990, Bulletin of Labour Statistics, Geneva (various issues).

Patrick, H.T. and T.P. Rohlen, 1987, Small-scale family enterprises, in: K. Yamamura and Y. Yasuba eds., The political economy of Japan; Vol 1: The domestic transformation (Stanford University Press, Stanford, CA) 331-384.

Potjes, J.C.A., M.A. Carree and A.R. Thurik, 1992, Japanese retail stores: regulation, retailerclient relations and the dual economy, Report 9245/A, (Econometric Institute, Erasmus University Rotterdam, Rotterdam, Netherlands).

Potjes, J.C.A., Y. Suzuki and A.R. Thurik, 1990, A floorspace productivity relationship for Japanese convenience store. Aoyama Business Review 15, 31-41.

Potjes, J.C.A. and A.R. Thurik, 1991, Japanese supermarket chains and labour costs; Part 1: Differing marketing strategies among chains, Journal of Marketing Channels 1(2), 53-73.

Potjes, J.C.A. and A.R. Thurik, 1992, Retail profit margins in Japan, Research Paper 9202 (Research Institute for Small and Medium-Sized Business in the Netherlands, Zoetermeer, Netherlands).

Ravesloot, K.A. and W.J.P. Vogelesang, 1989, De Nederlandse detailhandel in internationaal perspectief, (in Dutch), Dutch retail trade in international perspective (Research Institute for Small and Medium-Sized Business in the Netherlands, Zoetermeer, Netherlands).

Schmalensee, R., 1989, Inter-industry studies of structure and performance, R. Schmalensee and R.D. Willig eds., Handbook of industrial organization, Vol. 2 (Elsevier Science Publishers B.V., Amsterdam) 952-1009.

Simon, H., 1986, Market entry in Japan: barriers, problems and strategies, International Journal of Research in Marketing 3 105-116.

Small and Medium Enterprise Agency, 7975 through 1990, Chusho kigyo no genka (in Japanese), Costs of the small and medium-sized enterprises $(1973 ; 1974, \ldots, 1988)$, Tokyo.

Suzuki, Y., 1991, Large retail store law, presented at the Second Annual Global Marketing Conference: The Japanese Distribution System, of the $\Lambda$ merican Marketing $\Lambda$ ssociation, November 24-26, 1991 in Honolulu, HI.

Tajima, Y., 1971, How goods are distributed in Japan, translated from Japanese by J. Seward (Walton-Ridgeway, Tokyo).

US International Trade Commission, 1990, Phase I: Japan's Distribution System and Options for Improving US Access, USITC publication 2291, Washington, DC.

Yoshino, M.Y., 1971, Marketing in Japan: adaptations and innovations (The MIT Press, Cambridge, MA). 